\title{
Coordination Copolymerization of Polar Vinyl Monomers $\mathrm{H}_{2} \mathrm{C}=\mathbf{C H X} * *$
}

\author{
Andreas Berkefeld and Stefan Mecking*
}

copolymerization $\cdot$ homogeneous catalysis .

palladium $\cdot$ polymers $\cdot$ polyolefins

$O_{1}$ all polymerization methods, catalytic polymerization offers the broadest scope of microstructure control. Stereoregularity, comonomer incorporation and sequences, molecular weights, and molecular weight distributions can be controlled by the catalyst structure. ${ }^{[1]}$ Polyolefins are produced on a vast scale of nearly 100 million tons annually, predominantly by catalytic polymerization. High-density polyethylene (HDPE) and isotactic polypropylene are examples. These polymers are hydrocarbons without any heteroatom-containing functional groups, such as ester moieties.

Catalysts employed in industrial polyolefin production are based on early transition metals such as $\mathrm{Ti}, \mathrm{Zr}, \mathrm{Cr}$, or $\mathrm{V}$. Owing to their high oxophilicity, the polymerization-active metal centers interact strongly with oxygen- or nitrogencontaining moities, rendering them inactive for insertion polymerization. Thus, polar-substituted vinyl monomers $\mathrm{H}_{2} \mathrm{C}=\mathrm{CHX}$, of which vinyl acetate (VA), acrylates, and acrylonitrile (AN) are the major representatives, are homoand copolymerized by routes other than insertion polymerization, usually by free-radical polymerization. Polyolefins containing polar groups are prepared on a large scale in the form of ethylene-VA copolymers by high-pressure freeradical polymerization. Since the discoveries of Ziegler ${ }^{[2]}$ and Natta, ${ }^{[3]}$ the coordination copolymerization of polar-substituted vinyl monomers $\mathrm{H}_{2} \mathrm{C}=\mathrm{CHX}$ has been a challenge. Incorporation in polyolefins is of broad interest, for example, to increase interactions with polar surfaces, such as metals, or to achieve stability towards hydrocarbon solvents.

A major advance was achieved in the mid-1990s with Brookhart and co-workers' studies of olefin polymerization by cationic $\mathrm{Ni}^{\mathrm{II}}$ and $\mathrm{Pd}^{\mathrm{II}}$ diimine complexes. ${ }^{[4-7]}$ In comparison to the aforementioned early-transition-metal complexes, these late-transition-metal complexes are much less oxophilic. For the first time, ethylene or 1-olefins were copolymerized with acrylates in a catalytic fashion. ${ }^{[7]}$ Owing to the propensity of the $\mathrm{Pd}^{\mathrm{II}}$ complexes employed to "chain walk" ${ }^{[4,8]}[$ Eq. (1)]

[*] Dipl.-Chem. A. Berkefeld, Prof. Dr. S. Mecking Lehrstuhl für Chemische Materialwissenschaft Fachbereich Chemie, Universität Konstanz Universitätsstrasse 10, 78457 Konstanz (Germany) Fax: $(+49) 7531-88-5152$

E-mail: stefan.mecking@uni-konstanz.de

Homepage: http://www.chemie.uni-konstanz.de/agmeck/

[***: S.M. is indebted to the Fonds der Chemischen Industrie.
Dedicated to Professor Maurice Brookhart on the occasion of his 65th birthday on the growing chain during polymerization, highly branched amorphous polyethylenes with the acrylate repeat units located predominantly at the ends of branches are obtained (see also Scheme 2). ${ }^{[9]}$

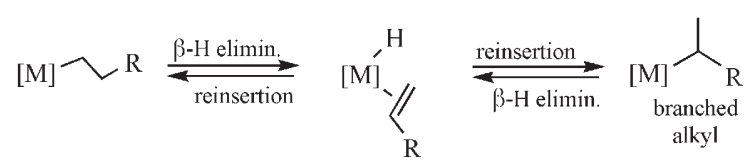

However, in contrast to acrylates, other common comonomers such as VA, AN, and vinyl chloride (VC) could not be copolymerized by these cationic complexes. Very recently, significant advances have been reported with neutral $\mathrm{Pd}^{\mathrm{II}}$ catalysts, which are highlighted herein. To rationalize these findings, it is instructive to consider the challenges in the copolymerization of apolar- and polar-substituted olefins (Scheme 1). These have been revealed by recent mechanistic studies, particularly by low-temperature NMR spectroscopy, of the reactivity of cationic species $\left(\mathrm{N}^{\wedge} \mathrm{N}\right) \mathrm{PdMe}^{+}$towards these monomers. ${ }^{[10]}$

A prerequisite for insertion of $\mathrm{CH}_{2}=\mathrm{CHX}$ is $\pi$ coordination through the olefinic double bond (formation of $\mathbf{1}$ ). This mode competes with $\kappa-\mathrm{X}$ coordination (formation of $\mathbf{3}$ ) and with coordination of apolar olefin (formation of 2 ). Competitive $\pi$ binding of apolar- versus polar-substiuted olefin $\left(K_{\mathrm{eq}}\right)$ is in favor of the former, owing to its stronger $\sigma$-donating capability. This tendency can be compensated to a certain extent by a higher rate of migratory insertion of the electronpoor polar-substituted olefin $\mathrm{CH}_{2}=\mathrm{CHX}\left(k_{1}\right.$ vs. $\left.k_{2}\right)$. In ethylene-methyl acrylate (MA) copolymerization, the interplay of these factors determines the copolymer composition. Of the specific monomers mentioned above, significant $\kappa-X$ coordination (3) was only observed in the case of AN. $\kappa-N$ coordination of the nitrile group predominates over $\pi$ coordination of the olefinic moiety (1), but even in this case the latter-though not directly observed-apparently occurs to a sufficient extent to allow for AN insertion. Note that studies of the reactivity of VA with the nickel species $\left(\mathrm{N}^{\wedge} \mathrm{N}\right) \mathrm{NiMe}^{+}$show that $\kappa-\mathrm{X}$ coordination is more pronounced with these more electrophilic metal centers, as expected; approximately equal portions of $\kappa-\mathrm{O}$ and $\pi$ binding are observed.

Migratory insertion in a 2,1-fashion affords an alkyl species with the $\mathrm{X}$ moiety on the $\alpha$-carbon atom (4). In 


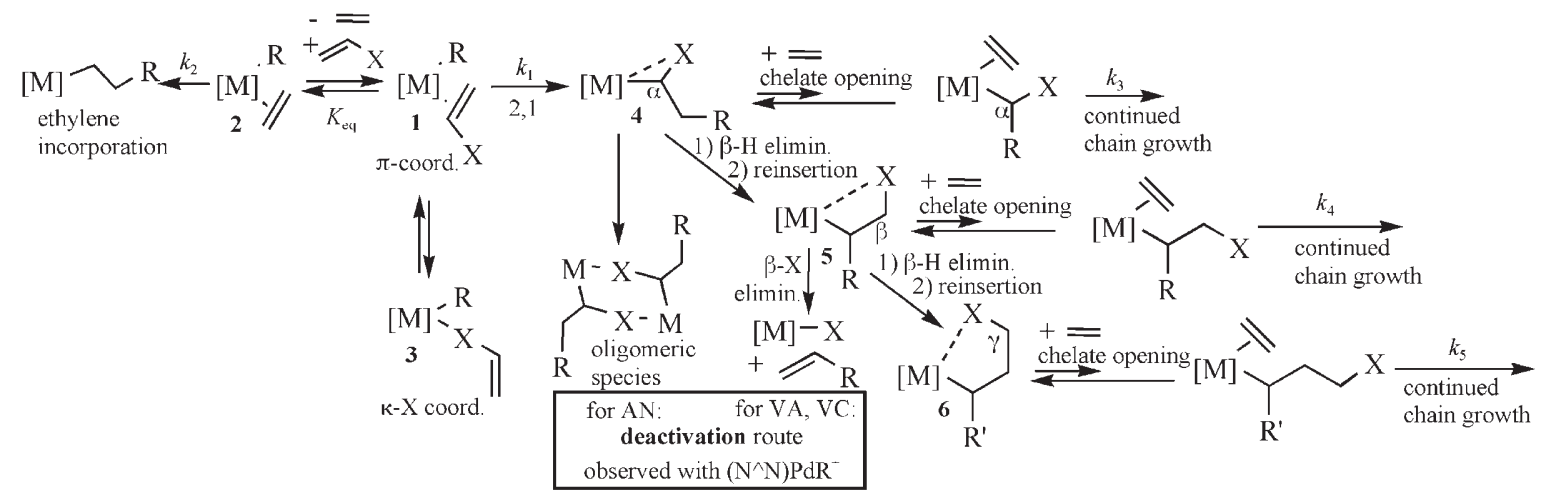

Scheme 1. Reaction steps in the copolymerization of ethylene with polar-substituted olefins $\mathrm{H}_{2} \mathrm{C}=\mathrm{CHX}$.

comparison to unsubstituted alkyls, this substitution can lower the reactivity in subsequent insertion reactions $\left(k_{3}\right)$, as observed for the VA and VC insertion products. ${ }^{[11]} \beta$-Hydride elimination, olefin rotation, and reinsertion [cf. Eq. (1)] afford a chelate 5 enlarged by one carbon atom relative to 4, with the $\mathrm{X}$ moiety on the $\beta$-carbon atom (a similar $\beta$-Xsubstituted product also results directly from the less common 1,2 -insertion in 1). For VA $(\mathrm{X}=\mathrm{OAc})$ and $\mathrm{VC}(\mathrm{X}=\mathrm{Cl})$, this species was found to be prone to $\beta-\mathrm{X}$ elimination as a decomposition route. A driving force is likely the high stability of the $\mathrm{M}-\mathrm{O}$ and $\mathrm{M}-\mathrm{Cl}$ bonds, respectively. Another sequence of $\beta$-hydride elimination, olefin rotation, and reinsertion starting from $\mathbf{5}$ affords an alkyl species with the $\mathrm{X}$ moiety on the $\gamma$-carbon atom $(\mathbf{6})$.

In 4-6, the $X$ group may coordinate in a chelating fashion as illustrated, for example, by the five-membered chelate complex $\left[\left(\mathrm{N}^{\wedge} \mathrm{N}\right) \mathrm{Pd}\left\{\kappa^{2}-\mathrm{CH}(\mathrm{Et})\left(\mathrm{OC}(O) \mathrm{CH}_{3}\right)\right\}\right]^{+}(4)$ formed by migratory insertion of VA into a $\mathrm{Pd}-\mathrm{Me}$ bond, or the sixmembered chelate complex $\left[\left(\mathrm{N}^{\wedge} \mathrm{N}\right) \mathrm{Pd}\right.$ $\left.\left\{\kappa^{2}-\left(\mathrm{CH}_{2}\right)_{3} \mathrm{C}(\mathrm{O}) \mathrm{OMe}\right\}\right]^{+}(\mathbf{6})$, which is the thermodynamically favored final product of MA insertion and subsequent rearrangements. Further chain growth requires the opening of these chelates by olefin coordination. Staying with the two aforementioned examples, chelate opening can be directly observed at low temperature, but at room temperature the equilibrium is much in favor of the chelate complex, which is indeed the resting state in ethylene-MA copolymerization. In the case of $\mathrm{AN}, 4$ rearranges to oligomeric species, which are rather stable owing to the strongly coordinating nitrile groups. They do not react further with AN or ethylene, which is also related to the retardation of migratory insertion by the $\alpha-X$ substitution of the palladium alkyl.

It is obvious that in the polymerization of polar monomers, and in particular of very challenging candidates such as VA or AN, among other things an appropriate electrophilicity of the metal center is required. On the one hand, too high an electrophilicity will result in undesired $\kappa$-X coordination of the functional group of the monomer and, after an insertion of the latter, in formation of stable chelates (or related oligomers) which are inert toward further reaction. On the other hand, too low an electrophilicity will result in a low reactivity for olefin insertion reactions in general. ${ }^{[12]}$ Also, a suppression of deactivation by $\beta-\mathrm{X}$ elimination is mandatory.
A highly interesting system, the broad versatility of which has only very recently been demonstrated, are catalysts based on 7. Formally a neutral $\mathrm{Pd}^{\mathrm{II}}$ complex, the sulfonate group as a

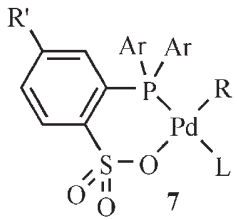

$\mathrm{Ar}=2-\mathrm{MeOC}_{6} \mathrm{H}_{4} ; 2,6-(\mathrm{MeO})_{2} \mathrm{C}_{6} \mathrm{H}_{3} ; \mathrm{Ph} ; \mathrm{R}^{\prime}=\mathrm{H}, \mathrm{Me}$ $\mathrm{R}=\mathrm{Me} ; \mathrm{L}=$ py, lutidine or $1 / 2 \mathrm{Me}_{2} \mathrm{NCH}_{2} \mathrm{CH}_{2} \mathrm{NMe}_{2}$ $\mathrm{R}, \mathrm{L}=2 \eta^{1}, 6,7$-tricyclo[5.2.1.0 $\left.0^{5,9}\right]$-deca-6-ene3-ethoxy-2-yl

$\eta^{3}$-allyl

$\kappa^{2}-\mathrm{C}, \mathrm{O}-C(\mathrm{Et}) \mathrm{OC}(O) \mathrm{Me}$

rather poor electron donor should result in a comparatively high electrophilicity relative to other neutral $\mathrm{Pd}^{\mathrm{II}}$ complexes, which to date generally have shown very little activity in olefin insertion polymerization or oligomerization. ${ }^{[13]}$ Catalysts of type 7 copolymerize ethylene with MA, as reported first by Drent et al. ${ }^{[14]} \mathrm{An}$ in situ catalyst prepared by reaction of $O$-sulfonated phosphine, $\mathrm{Ar}_{2} \mathrm{PC}_{6} \mathrm{H}_{4} \mathrm{SO}_{3} \mathrm{H}$, with $\left[\mathrm{Pd}^{0}\right.$ (dibenzylideneacetone) $]$ was utilized. Remarkably, a linear ethylene-MA copolymer is obtained (Scheme 2; in

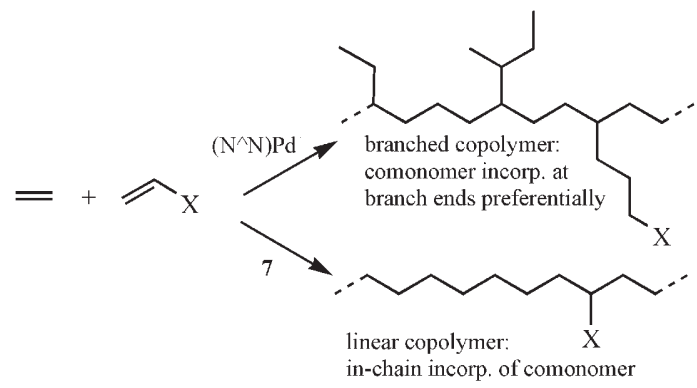

Scheme 2. Microstructure of ethylene- $\left(\mathrm{H}_{2} \mathrm{C}=\mathrm{CHX}\right)$ copolymers.

the homopolymerization of ethylene, linear polyethylene is formed). ${ }^{[9]}$ Theoretical studies suggest that the absence of "chain walking" [Eq. (1)] is due to an increased barrier to $\beta$ hydride elimination relative to the cationic $\mathrm{Pd}$ diimine systems. ${ }^{[15]}$ As a typical example, polymerization at $80^{\circ} \mathrm{C}$ and $30 \mathrm{~atm}$ ethylene pressure for $15 \mathrm{~h}$ proceeded with an average activity of $160 \mathrm{TOh}^{-1}(\mathrm{TO}=$ mole of monomer 
converted per mole of metal present in the reaction mixture). A linear copolymer with an acrylate incorporation of $13 \mathrm{~mol} \%$ and a number average molecular weight of $M_{\mathrm{n}}=$ $1.3 \times 10^{4} \mathrm{~g} \mathrm{~mol}^{-1}\left(M_{\mathrm{w}} / M_{\mathrm{n}} 1.6\right)$ was obtained. The reaction conditions correspond to roughly equal concentrations of the two comonomers in the reaction mixture, that is, the aforementioned copolymer composition corresponds to incorporation of ethylene being somewhat preferred over incorporation of MA. The rate of the copolymerization is lower than ethylene homopolymerization and decreases with increasing acrylate incorporation. This effect is due to a relatively slow insertion of ethylene after an acrylate insertion. Possible origins are the necessity of chelate opening (of 4) and a higher barrier of insertion in an alkyl species $\alpha$-substituted with an electron-withdrawing group than in an unsubstituted alkyl species. End-group analyses show that chain transfer occurs preferentially after an acrylate insertion.

Relative to the analogues with unsubstituted phenyl groups bound to the phosphorus donor $(\mathrm{Ar}=\mathrm{Ph})$, higher rates of polymerization are observed with $o$-methoxy-substituted aryl moieties. It has been suggested that a weak intermittent interaction of the OMe moiety with the metal center could promote displacement of coordinated Lewis basic comonomer. ${ }^{[16]}$

The synthesis and structural analysis of complexes $\mathbf{7}^{[14 c, 17,21,25 c, 26,27]}$ which are active as single-component catalyst precursors for polymerizations, confirm the chelating $\kappa^{2}-\mathrm{P}, \mathrm{O}$ coordination mode of the sulfonated phosphine. Although sulfonates bind relatively weakly to $\mathrm{Pd}^{\mathrm{II}},{ }^{[18]}$ in the chelates 7 this group is not displaced even by an excess of acetonitrile or pyridine.

Polymerizations with $\mathbf{7}$ can also be carried out in aqueous systems, to afford polymer latexes, that is, colloidally stable aqueous dispersions of sub-micrometer polymer particles. Polyacrylate- and VA-based dispersions, produced by freeradical polymerization, are used on a large scale as environmentally benign coatings and paints. Catalytic polymerizations in aqueous emulsions enable the preparation of dispersions inaccessible by other means, for example, polyolefin dispersions. ${ }^{[19]}$ In such dispersions, incorporation of a polar-substituted monomer can be highly desirable to improve the adhesion of coatings to polar surfaces and the colloidal stability of the dispersions. With catalysts of type $\mathbf{7}$, the catalytic copolymerization of ethylene and MA can be carried out in aqueous emulsion to afford colloidally stable ethylene-MA copolymer latexes. ${ }^{[20]}$ For example, an aqueous dispersion with a solids content of $4.5 \mathrm{wt} \%$ of a low molecular weight $\left(M_{\mathrm{n}}=5 \times 10^{3} \mathrm{~g} \mathrm{~mol}^{-1}\right)$ copolymer with $2.7 \mathrm{~mol} \% \mathrm{MA}$ incorporation was reported to be formed with an average catalyst activity of $440 \mathrm{TOh}^{-1}$.

Recent reports have revealed that complexes 7 even enable catalytic copolymerizations of the challenging monomers AN and VA. Thus, exposure of 7 to ethylene and AN results in copolymer formation. ${ }^{[21]}$ With an average activity of about $10 \mathrm{TO} \mathrm{h}^{-1}$ under typical reaction conditions $\left(100^{\circ} \mathrm{C}\right.$,

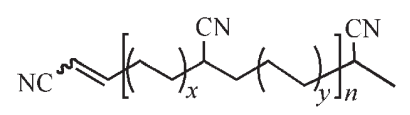

$30 \mathrm{~atm}$ ethylene pressure, $120 \mathrm{~h}$ ), the reaction is slow but occurs in a catalytic fashion. Incorporation of $\mathrm{AN}$ in the polymer increases with increasing concentration of $\mathrm{AN}$ in the reaction mixture, and the overall polymerization rate decreases. This retardation very likely results from $\kappa$-X coordination $(\mathrm{X}=\mathrm{CN})$ of free $\mathrm{AN}$ or $\mathrm{AN}$ incorporated in the polymer (or both). The low molecular weight polymers formed $\left(M_{\mathrm{n}}=10^{3}-10^{4} \mathrm{~g} \mathrm{~mol}^{-1}\right)$ contained up to $9 \mathrm{~mol} \% \mathrm{AN}$. The AN is distributed in approximately equal amounts in the polymer backbone and in end groups that are derived from the AN monomer. Apparently, chain transfer occurs preferentially after an AN insertion, that is, increasing incorporation of the comonomer results in a decrease of molecular weights. Incorporation of $\mathrm{AN}$ is also the preferred mode of initiation of a new chain.

Catalysts based on $\mathbf{7}$ are also capable of copolymerizing alkyl vinyl ethers (VE) with ethylene. ${ }^{[22]}$ Issues in the copolymerization of these electron-rich functionalized monomers differ from the electron-poor monomers discussed above. With $\left(\mathrm{N}^{\wedge} \mathrm{N}\right) \mathrm{PdMe}{ }^{+}$, rapid cationic polymerization of VE and catalyst decomposition occurred. ${ }^{[10 \mathrm{~g}]}$ With 7, a linear copolymer with, for example, $2 \mathrm{~mol} \% \mathrm{VE}$ incorporation and a molecular weight of $M_{\mathrm{n}}=5 \times 10^{3} \mathrm{~g} \mathrm{~mol}^{-1}$ was formed with an average activity of $350 \mathrm{TOh}^{-1}$. Again, chain transfer is more likely after an insertion of the functionalized comonomer, but VE-derived repeat units are also incorporated within the main chain. The ethylene-VE copolymers can be converted to $\mathrm{HO}$ - or Br-substituted linear polyethylenes by postpolymerization reactions.

Coordination polymerization of VA by 7 was realized by copolymerization with carbon monoxide. Copolymerization of apolar olefins, particularly ethylene, with $\mathrm{CO}$ by cationic $\mathrm{Pd}^{\mathrm{II}}$ diphosphine complexes has been studied intensely. ${ }^{[23]}$ With high catalyst activities of up to $10^{5} \mathrm{TOh}^{-1}$, perfectly alternating copolymers $\left[\mathrm{CH}_{2} \mathrm{CH}_{2} \mathrm{C}(\mathrm{O})\right]_{n}$ are obtained. The strictly alternating structure results from the much stronger binding to the metal center of $\mathrm{CO}$ versus olefin, favoring insertion of $\mathrm{CO}$ into $\mathrm{PdCH}_{2} \mathrm{CH}_{2} \mathrm{C}(\mathrm{O}) \mathrm{R}$ over olefin insertion, and from the thermodynamic unfavorability of double $\mathrm{CO}$ insertion. An incorporation of polar-substituted olefins is possible in the form of terpolymerization of $\mathrm{CO}$, ethylene, and MA or VA. Alternating olefin-CO terpolymers are obtained. Incorporation of ethylene is favored over the electron-poor olefin; the latter was reported to be incorporated with up to $8 \mathrm{~mol} \%$ (MA) and $1.5 \mathrm{~mol} \%$ (VA). ${ }^{[24]}$ In contrast to these alternating copolymerizations, with 7 non-alternating ethylene-CO copolymers are obtained, which contain subsequent ethylene repeat units, $\left[\left\{\mathrm{CH}_{2} \mathrm{CH}_{2}\right\}_{x} \mathrm{C}(\mathrm{O})\right]_{n}(x \geq 1) .{ }^{[25]}$ This result requires that the relative binding strength of ethylene is sufficiently high that opening of intermediately formed chelates $\left[\left(\mathrm{P}^{\wedge} \mathrm{O}\right) \mathrm{Pd}\left\{\kappa^{2}-\mathrm{CH}_{2} \mathrm{CH}_{2} \mathrm{C}(\mathrm{O}) \mathrm{R}\right\}\right]$ also occurs by the olefin; a low propensity for $\beta$-hydride elimination of the palladium alkyl species resulting from this insertion is also required.

The exposure of 7 to VA and $\mathrm{CO}$ results in alternating insertions to afford an alternating VA-CO copolymer [Eq. (2)]. ${ }^{[26]}$

The reaction is relatively slow, typically proceeding with $20 \mathrm{TOh}^{-1}\left(70^{\circ} \mathrm{C}, 60 \mathrm{~atm} \mathrm{CO}, 20 \mathrm{~h}\right)$. The copolymers have 


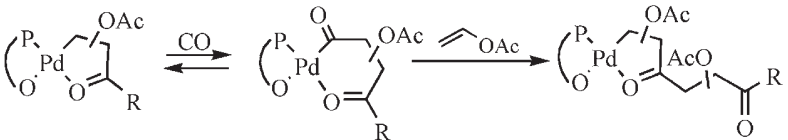

molecular weights of $M_{\mathrm{n}}=4 \times 10^{4} \mathrm{~g} \mathrm{~mol}^{-1}\left(M_{\mathrm{w}} / M_{\mathrm{n}} 1.4\right)$. Apparently, the relative binding strength even of the electron-poor olefin VA is high enough for opening by VA of the presumably occuring chelates $\left[\left(\mathrm{P}^{\wedge} \mathrm{O}\right) \mathrm{Pd}\left\{\kappa^{2}-C(\mathrm{O}) \mathrm{CH}\right.\right.$ $\left.\left.(\mathrm{OAc}) \mathrm{CH}_{2} \mathrm{C}(O) \mathrm{R}\right\}\right]$. Note that a variety of the abovementioned critical issues in copolymerization of apolar olefins with $\mathrm{H}_{2} \mathrm{C}=\mathrm{CHX}$ (Scheme 1) do not apply to the same extent to alternating olefin- $\mathrm{CO}$ copolymerizations.

Concerning the regiochemistry of insertion of $\mathrm{H}_{2} \mathrm{C}=\mathrm{CHX}$ in the above copolymerizations with $\mathbf{7}$, end-group analyses of the ethylene-MA, ethylene-AN, and VA-CO copolymers, and studies of the insertion of VA into $\mathrm{Pd}-\mathrm{Me}$ bonds, reveal 2,1-insertion to be preferred. This finding strongly suggests that it is also the preferred insertion mode in chain growth, similar to polymerizations with the cationic diimines (Scheme 1).

Further optimization of the structure of catalyst precursors 7 resulted in substantially increased ethylene polymerization activities and polymer molecular weights. With bulky substituted aryl groups on the phosphine donor and a weakly coordinating tertiary amine as a labile ligand $\mathrm{L}(\mathrm{Ar}=2-(2-$ methoxyphenyl)phenyl; $\mathrm{L}=\mathrm{Me}_{2} \mathrm{NCH}_{2} \mathrm{CH}_{2} \mathrm{NMe}_{2}$ ), at $100^{\circ} \mathrm{C}$ ethylene homopolymerization proceeds with an average activity of $7 \times 10^{5} \mathrm{TOh}^{-1}$ in a one-hour polymerization experiment. A linear polyethylene with $M_{\mathrm{n}}=1.4 \times 10^{5} \mathrm{~g} \mathrm{~mol}^{-1}$ $\left(M_{\mathrm{w}} / M_{\mathrm{n}} 3.0\right)$ was obtained. In a typical copolymerization experiment with this catalyst, an ethylene-MA copolymer with $6 \mathrm{~mol} \%$ MA incorporation and $M_{\mathrm{n}}=10^{4} \mathrm{~g} \mathrm{~mol}^{-1}$ is formed with an average catalyst activity of $7 \times 10^{2} \mathrm{TOh}^{-1}$. ${ }^{[27]}$

A comparison of polymerizations with 7 and cationic $\mathrm{Pd}^{\mathrm{II}}$ dimine catalysts $\left(\mathrm{N}^{\wedge} \mathrm{N}\right) \mathrm{PdR}^{+}$is instructive: 1) linear (semicrystalline) polymers are obtained with $\mathbf{7}$, while highly branched amorphous polymers are obtained with $\left(\mathrm{N}^{\wedge} \mathrm{N}\right) \mathrm{PdR}^{+}$, likely owing to slow $\beta$-hydride elimination relative to chain growth with 7.2) $\kappa-X$ coordination in general is less an issue with the less electrophilic 7. 3) On the other hand, the available data suggest that intrinsic olefin insertion rates are higher in the more electrophilic cationic $\left(\mathrm{N}^{\wedge} \mathrm{N}\right) \mathrm{PdR}^{+}$. However, a better temperature stability of $\mathbf{7}$ allows for compensation of this effect by carrying out polymerization at higher temperature. 4) Comonomer incorporations achieved and molecular weights and catalyst activities reported to date in ethylene-MA copolymerization with 7 and $\left(\mathrm{N}^{\wedge} \mathrm{N}\right) \mathrm{PdR}^{+}$are comparable. 5) Possibly, lower differences in relative binding strength of the olefin versus the more strongly coordinating $\mathrm{CO}$ in $\mathbf{7}$ in comparison to cationic $\mathrm{Pd}^{\mathrm{II}}$ complexes enhance CO-VA and non-alternating ethylene-CO copolymerization with 7.

In summary, neutral phosphinosulfonate $\mathrm{Pd}^{\mathrm{II}}$ chelates $\mathbf{7}$ enable significant advances in the quest for catalytic copolymerization of apolar olefins with polar-substituted vinyl monomers $\mathrm{H}_{2} \mathrm{C}=\mathrm{CHX}$. Perhaps most notably so far, catalytic ethylene-AN copolymerization is possible. Catalyst activities reported to date are moderate, owing to a low rate of polymerization. Increasing the intrinsic olefin insertion rates in $\mathbf{7}$ or related systems, possibly by tailoring the steric bulk experienced by the metal center, will be one issue to be addressed.

Published online: February 22, 2008

[1] a) Ziegler Catalysts (Eds.: G. Fink, R. Mülhaupt, H. H. Brintzinger), Springer, Berlin, 1995; b) R. Mülhaupt, Macromol. Chem. Phys. 2003, 204, 289-327.

[2] a) K. Ziegler, H. Breil, E. Holzkamp, H. Martin, DE 973626, 1953; b) K. Ziegler, E. Holzkamp, H. Breil, H. Martin, Angew. Chem. 1955, 67, 426; c) K. Ziegler, E. Holzkamp, H. Breil, H. Martin, Angew. Chem. 1955, 67, 541-547.

[3] G. Natta, P. Pino, P. Corradini, F. Danusso, E. Mantica, G. Mazzanti, G. Moraglio, J. Am. Chem. Soc. 1955, 77, 1708-1710.

[4] L. K. Johnson, C. M. Killian, M. Brookhart, J. Am. Chem. Soc. 1995, 117, 6414-6415.

[5] Reviews: a) S. D. Ittel, L. K. Johnson, M. Brookhart, Chem. Rev. 2000, 100, 1169-1203; b) V. C. Gibson, S. K. Spitzmesser, Chem. Rev. 2003, 103, 283-315; c) S. Mecking, Angew. Chem. 2001, 113, 550-557; Angew. Chem. Int. Ed. 2001, 40, 534-540; d) S. Mecking, Coord. Chem. Rev. 2000, 203, 325-351; e) Z. Guan, Chem. Eur. J. 2002, 8, 3086-3092; f) L. S. Boffa, B. M. Novak, Chem. Rev. 2000, 100, 1479-1493.

[6] Earlier work demonstrating tolerance of $\mathrm{Ni}^{\mathrm{II}}$ oligomerization or polymerization catalysts towards polar compounds: a) W. Keim, Chem. Ing. Tech. 1984, 56, 850-853; b) U. Klabunde, S. D. Ittel, J. Mol. Catal. 1987, 41, 123-134.

[7] a) L. K. Johnson, S. Mecking, M. Brookhart, J. Am. Chem. Soc. 1996, 118, 267-268; b) S. Mecking, L. K. Johnson, L. Wang, M. Brookhart, J. Am. Chem. Soc. 1998, 120, 888-899.

[8] See also: a) V. M. Möhring, G. Fink, Angew. Chem. 1985, 97 , 982-984; Angew. Chem. Int. Ed. Engl. 1985, 24, 1001-1003; b) Z. Guan, P. M. Cotts, E. F. McCord, S. J. McLain, Science 1999, 283, 2059-2062.

[9] Polymerizations with $\left(\mathrm{N}^{\wedge} \mathrm{N}\right) \mathrm{NiR}^{+}$can afford linear ethyleneMA copolymers. The reaction is slow and requires high temperatures, presumably owing to the formation of rather stable chelates (4) as intermediates: a) L. Johnson, A. Bennett, K. Dobbs, E. Hauptman, A. Ionkin, S. Ittel, E. McCord, S. McLain, C. Radzewich, Z. Yin, L. Wang, Y. Wang, M. Brookhart, Polym. Mater. Sci. Eng. 2002, 86, 319; b) L. Johnson, L. Wang, S. McLain, A. Bennett, K. Dobbs, E. Hauptman, A. Ionkin, S. Ittel, K. Kunitsky, W. Marshall, E. McCord, C. Radzewich, A. Rinehart, K. J. Sweetman, Y. Wang, Z. Yin, M. Brookhart, ACS Symp. Ser. 2003, 857, 131-142.

[10] a) S. R. Foley, R. A. Stockland, H. Shen, R. F. Jordan, J. Am. Chem. Soc. 2003, 125, 4350-4361; b) B. S. Williams, M. D. Leatherman, P. S. White, M. Brookhart, J. Am. Chem. Soc. 2005, 127, 5132-5146; c) F. Wu, S. R. Foley, C. T. Burns, R. F. Jordan, J. Am. Chem. Soc. 2005, 127, 1841-1853; see also: d) L. F. Groux, T. Weiss, D. N. Reddy, P. A. Chase, W. E. Piers, T. Ziegler, M. Parvez, J. Benet-Buchholz, J. Am. Chem. Soc. 2005, 127, 1854-1869; e) H. W. Boone, P. S. Athey, M. J. Mullins, D. Philipp, R. Muller, W. A. Goddard, J. Am. Chem. Soc. 2002, 124, 8790-8791; f) W. Li, X. Zhang, A. Meetsma, B. Hessen, J. Am. Chem. Soc. 2004, 126, 12246-12247; g) S. Luo, R. F. Jordan, J. Am. Chem. Soc. 2006, 128, 12072-12073; h) D. M. Philipp, R. P. Muller, W. A. Goddard, J. Storer, M. McAdon, M. Mullins, $J$. Am. Chem. Soc. 2002, 124, $10198-10210$; i) C. S. Popeney, D. H. Camacho, Z. Guan, J. Am. Chem. Soc. 2007, 129, 10062-10063.

[11] a) S. R. Foley, H. Shen, U. A. Qadeer, R. F. Jordan, Organometallics 2004, 23, 600-609; see also: b) T. Fujita, K. Nakano, M. Yamashita, K. Nozaki, J. Am. Chem. Soc. 2006, 128, 1968-1975.

[12] M. J. Szabo, R. F. Jordan, A. Michalak, W. E. Piers, T. Weiss, S.-Y. Yang, T. Ziegler, Organometallics 2004, 23, 5565-5572. 
[13] G. J. P. Britovsek, W. Keim, S. Mecking, D. Sainz, T. Wagner, $J$. Chem. Soc. Chem. Commun. 1993, 1632-1634.

[14] a) E. Drent, R. van Dijk, R. van Ginkel, B. van Oort, R. I. Pugh, Chem. Commun. 2002, $744-745$; see also: b) E. Drent, D. H. L. Pello, W. W. Jager (Montell), Eur. Pat. 589527 B1, 1994; c) T. Kochi, K. Yoshimura, K. Nozaki, Dalton Trans. 2006, 25-27.

[15] A. Haras, G. D. W. Anderson, A. Michalak, B. Rieger, T. Ziegler, Organometallics 2006, 25, 4491-4497.

[16] A similar enhancing effect of $o$-methoxy substituents has previously been observed in the alternating copolymerization of ethylene with $\mathrm{CO}$ by cationic $\mathrm{Pd}^{\mathrm{II}}$ diphosphine complexes: J. A. van Doorn, R. L. Wife, EP296687B1, 1994.

[17] S. Liu, S. Borkar, D. Newsham, H. Yennawar, A. Sen, Organometallics 2007, 26, 210-216.

[18] B. A. Markies, K. A. N. Verkerk, M. H. P. Rietveld, J. Boersma, H. Kooijman, A. L. Spek, G. van Koten, J. Chem. Soc. Chem. Commun. 1993, 1317-1319.

[19] a) F. M. Bauers, S. Mecking, Angew. Chem. 2001, 113, 3112 3115; Angew. Chem. Int. Ed. 2001, 40, 3020-3022; b) R. Soula, C. Novat, A. Tomov, R. Spitz, J. Claverie, X. Drujon, J. Malinge, T. Saudemont, Macromolecules 2001, 34, 2022-2026; reviews: c) S. Mecking, Colloid Polym. Sci. 2007, 285, 605-619; d) S. Z. D. Cheng, Nature 2007, 448, 1006-1007.

[20] J. P. Claverie, B. L. Goodall, K. M. Skupov, P. R. Marella, J. Hobbs, Polym. Prepr. Am. Chem. Soc. Div. Polym. Chem. 2007, 48, 191-192.
[21] T. Kochi, S. Noda, K. Yoshimura, K. Nozaki, J. Am. Chem. Soc. 2007, 129, 8948-8949.

[22] S. Luo, J. Vela, G. R. Lief, R. F. Jordan, J. Am. Chem. Soc. 2007, 129, 8946-8947.

[23] Reviews: a) A. Sen, Acc. Chem. Res. 1993, 26, 303-310; b) E. Drent, P. H. M. Budzelaar, Chem. Rev. 1996, 96, 663-681; mechanistic studies: c) F. Rix, M. Brookhart, P. S. White, J. Am. Chem. Soc. 1996, 118, 4746-4764.

[24] a) E. Drent (Shell), EP 251373 B1, 1992; b) related mechanistic studies on acrylate insertion in cationic $\mathrm{Pd}^{\mathrm{II}}$ acyl complexes: P. Braunstein, C. Frison, X. Morise, Angew. Chem. 2000, 112, 2989-2992; Angew. Chem. Int. Ed. 2000, 39, 2867-2870.

[25] a) E. Drent, R. van Dijk, R. van Ginkel, B. van Oort, R. I. Pugh, Chem. Commun. 2002, 964-965; b) E. Drent, D. H. L. Pello (Shell), EP632084B1, 1995; c) A. K. Hearley, R. J. Nowack, B. Rieger, Organometallics 2005, 24, 2755-2763; d) A. Haras, A. Michalak, B. Rieger, T. Ziegler, J. Am. Chem. Soc. 2005, 127, $8765-8774$; e) D. K. Newsham, S. Borkar, A. Sen, D. M. Conner, B. L. Goodall, Organometallics 2007, 26, 3636-3638.

[26] T. Kochi, A. Nakamura, H. Ida, K. Nozaki, J. Am. Chem. Soc. 2007, 129, 7770-7771.

[27] K. M. Skupov, P. R. Marella, M. Simard, G. P. A. Yap, N. Allen, D. Conner, B. L. Goodall, J. P. Claverie, Macromol. Rapid Commun. 2007, 28, 2033-2038. 